\title{
PENINGKATAN KESEJAHTERAAN MASYARAKAT DAN IZIN USAHA PENGELOLAAN HUTAN KEMASYARAKATAN (IUPHKM) DI PEKON AIR NANINGAN, KABUPATEN TANGGAMUS
}

\author{
Prayudha Ananta \\ Ekonomi Pembangunan, Universitas Lampung \\ email: prayudha_ananta@yahoo.com, prayudha.ananta@feb.unila.ac.id
}

\begin{abstract}
Provision of IUPHKm by the Ministry of Environment and Forestry (KLHK) is to improve the people's economy. Social forestry which was once illegally managed by the people, has now been legalized by the government through the KLHK. This study aims to find out how the impact of the provision of IUPHKm on farmer welfare in Air Naningan Village, Tanggamus Regency. The method used is an exploratory and descriptive method. The analysis used is crosstabulation. The results of this study were that after farmers in Air Naningan Village obtaining IUPHKm, their economy is increasesing as indicatet by : (1) their income increased by an average of 142.73 percent; (2) they are able to buy 1 to 3 units of motorcycles; (3) they have a permanent house.
\end{abstract}

Keywords: Hutan kemasyarakatan, Pekon Air Naningan

\section{PENDAHULUAN}

Konsep hutan untuk rakyat pada WFC ke8 tahun 1978 mengandung makna bahwa pembangunan hutan harus diarahkan untuk pembangunan masyarakat lokal (forestry for local community development). Tujuannya adalah untuk meningkatkan standar kehidupan penduduk perdesaan di sekitar hutan dengan cara melibatkan mereka dalam proses pengambilan keputusan dan berbagai kegiatan pengelolaan hutan sesuai dengan kearifan lokal. Sejak saat itulah lahir paradigma baru dalam pembangunan hutan bernama perhutanan sosial (social forestry).

Sebagai suatu paradigma yang baru saja lahir dalam pengelolaan hutan, terdapat banyak pengertian dan definisi tentang perhutanan sosial. Menurut Simon (1995) Perhutanan sosial adalah suatu strategi yang menitikberatkan pada pemecahan masalah-masalah penduduk lokal dan pemeliharaan lingkungan. Oleh karena itu, hasil utama kehutanan tidak semata-mata kayu. Lebih dari itu kehutanan dapat diarahkan untuk menghasilkan berbagai macam komoditi sesuai dengan kebutuhan penduduk di suatu wilayah, termasuk kayu bakar, pangan, pakan ternak, buah, air, satwa liar, keindahan, dan lainnya.

Wacana mengenai hutan kemasyarakatan sudah lama muncul, tepatnya tahun 1995. Ditandai dengan Keputusan Menteri Kehutanan Nomor 622/Kpts-II/1995 tentang Pedoman Hutan Kemasyarakatan yang bertujuan untuk menjawab tuntutan para pihak karena program HPH Bina Desa Hutan ternyata tidak mampu memecahkan permasalahan yang terdapat di masyarakat lokal. Dasar hukum HKm di Indonesia baru muncul dalam PP Nomor 6 Tahun 2007 sebagai revisi PP Nomor 34 Tahun 2002. Di dalam PP Nomor 6 Tahun 2007 ini yang dimaksud dengan $\mathrm{HKm}$ yaitu hutan negara yang pemanfaatan utamanya ditujukan untuk memberdayakan masyarakat.

Sebagaimana diterangkan dalam pasal 11 dari PP Nomor 6 Tahun 2007 tersebut 
bahwa: "Pada areal tertentu dari kawasan hutan sebagaimana dimaksud dalam Pasal 3 ayat 2 dapat ditetapkan oleh Pemerintah sebagai hutan kemasyarakatan, hutan adat, hutan desa, dan kawasan hutan dengan tujuan khusus (KHDTK)". Selain itu di dalam PP Nomor 6 Tahun 2007 juga menerangkan tentang ragam pemanfaatan hutan yang salah satunya adalah Ijin Pemanfaatan Hasil Hutan Kayu (IPHHK) dan Ijin Pemanfaatan Hasil Hutan Bukan Kayu (IPHHBK) yang menjadi lahan garap dalam program $\mathrm{HKm}$.

Hingga tahun 2017 pemberian izin usaha pemanfaatan hutan kemasyarakatan sendiri telah mencapai 301.548,67 $\mathrm{Ha}$ yang tersebar di 26 provinsi di Indonesia sedangkan untuk pencadangan area HKm sampai dengan tahun 2017 sudah seluas $432.598,86 \mathrm{Ha}$. Selisih angka pencadangan area $\mathrm{HKm}$ dan pemberian IUPHKm ini menjadi peluang bagi masyarakat sekitar hutan untuk mendapat akses kelola lahan lebih luas. IUPHKm tersebar di 26 provinsi di Indonesia.

Capaian IUPHKm hingga Desember 2017 masih dibawah angka penetapan areal kerja HKm. Provinsi Lampung mendapatkan IUHKm paling luas yaitu 109.360,73 Ha dan Bali mendapat IUPHKm paling sedikit hanya sebesar 150 ha. Luasan ini dapat meningkat mengingat data penetapan areal $\mathrm{HKm}$ yang belum sama dengan data IUPHKm. Pada data penetapan areal HKm Provinsi Lampung telah ditetapkan seluas 111.115,61 Ha masih jauh diatas capaian luas HKm yang telah mendapat IUPHKm.

Dengan telah diberikannya IUPHKm, maka penulisingin mengetahui perbedaan kesejahteraan sebelum dan setelah perizinan pengelolaan $\mathrm{HKm}$ di Pekon Air Naningan.

\section{KERANGKA PEMIKIRAN}

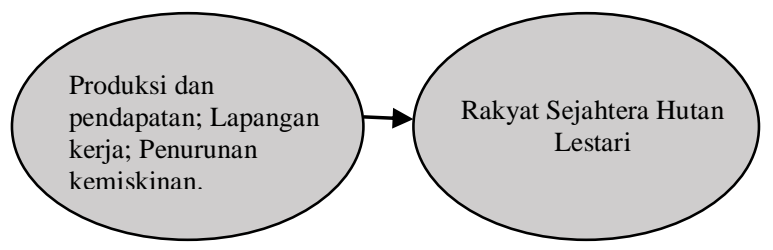

Gambar 1. Kerangka Pemikiran

Berbasis pada aspek ekonomi, yakni dampak ekonomi mewujudkan kesejahteraan masyarakat serta kelestarian. Untuk mengidentifikasi dampak ekonomi akan dilihat dari indikator- indikator ekonomi sebagai berikut: (1) Jumlah produksi dan pendapatan petani; (2) Lapangan kerja yang muncul dari keberadan HKm; (3) Penurunan kemiskinan.

\section{METODE PENELITIAN}

Artikel ini akan mengelaborasi sejauh mana dampak peningkatan kesejahteraan ditinjau dari dimensi ekonomi terhadap masyarakat di sekitar hutan. Metode penelitian yang digunakan dalam penelitian ini adalah eksploratif dan deskriptif analitik. Penggunaan metode ini diharapkan mampu mengelaborasi dan mempermudah proses penggalian informasi selama penelitian berlangsung.

Identifikasi dampak ekonomi dari perhutanan sosial dilakukan di Pekon Air Naningan, Kabupaten Tanggamus, Provinsi Lampung. Provinsi Lampung merupakan salah satu provinsi selain Yogyakarta yang sudah ditetapkan sebagai provinsi percontohan perhutanan sosial di Indonesia (KLHK, 2017).

Unit analisis dalam penelitian ini adalah Kelompok $\mathrm{HKm}$ dan masyarakat sekitar hutan sebagai penerima manfaat adanya HKm. Teknik penentuan informan dilakukan dengan metode cluster sampling dan purposive sampling. Kriteria responden: 1) merupakan petani kopi 
pemilik persil (lahan); 2) tergabung dalam kelompok tani.

Keterbatasan penelitian ini adalah petani baru 1-2 tahu memiliki lahan persil sendiri. Perlu dilakukan kajian lebih mendalam untuk jangka panjang.

\section{HASIL DAN PEMBAHASAN}

\section{Pendapatan}

\section{Gambar 2. Peningkatan Produksi Setelah Mendapat SK HKm}

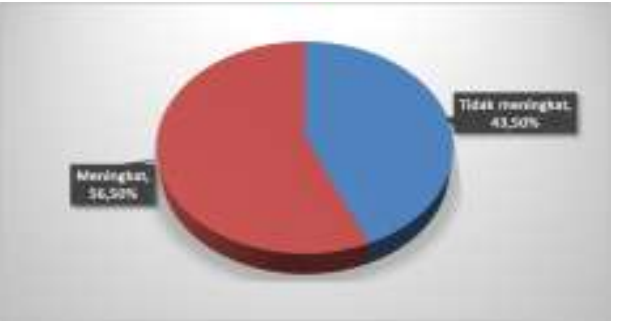

Sumber: Hasil olahan data primer

Para petani baik di Pekon Air Naningan menanam kopi sebagai komoditas utama, ditambah para petani juga menanam tanaman sampingan, berupa cabai, pisang, jagung, lada, dan sebagainya. Izin yang diberikan oleh pemerintah untuk mengelola lahan sangat signifikan dirasakan meningkatkan produksi. Dengan diberikannya izin, keleluasaan dan kenyamanan petani mengelola lahan garapannya (persil) untuk ditanami kopi dan tanaman sampingan.

Berdasarkan data total pendapatan yang diperoleh, rata-rata pendapatan adalah sebesar Rp28.340.724. Rata-rata pendapatan berada pada Kelas 2. Hal ini berarti berdasarkan Gambar 3 hanya terdapat 21,5persen petani telah memiliki total pendapatan lebih dari rata-rata, yakni petani yang berada pada Kelas 3 hingga Kelas 8. Sebanyak 25persen berada pada kelas pendapatan rata-rata (interval 20.000 - 39.900), dan lebih dari separuhnya berada pada interval $1.000-19.999$ yang masih berpendapatan dibawah rata-rata (53persen).

\section{Gambar 3. Interval Pendapatan per Tahun}

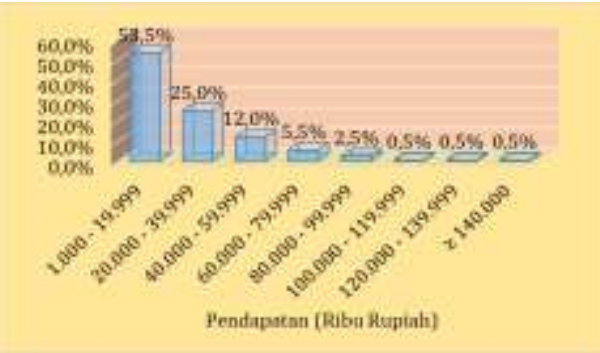

Sumber: Hasil olahan data primer

Terdapat tiga sumber pendapatan petani, yaitu: (1) Pendapatan dari tanaman utama;

(2) Pendapatan dari tanaman sampingan;

(3) Pendapatan dari ternak. Tabel 1 memperlihatkan proporsi masing-masing biaya terhadap total pendapatan. Rata-rata proporsi pendapatan tanaman utama adalah sebesar 0,473 , berada pada interval $0,401-0,5$.

Tabel 1. Proporsi Pendapatan Tanaman Utama, Sampingan, dan Ternak

\begin{tabular}{|c|r|r|r|}
\hline $\begin{array}{c}\text { Interval } \\
\text { Proporsi } \\
\text { Pendapatan }\end{array}$ & \multicolumn{1}{c|}{ Utama } & Sampingan & Ternak \\
\cline { 2 - 4 } & \multicolumn{1}{|c|}{$\%$} & \multicolumn{1}{c|}{$\%$} \\
\hline $0,000-0,1$ & 39,5 & 39,5 & 69 \\
\hline $0,101-0,2$ & 2 & 14,5 & 6,5 \\
\hline $0,201-0,3$ & 2 & 4,5 & 5,5 \\
\hline $0,301-0,4$ & 2,5 & 5,5 & 4,5 \\
\hline $0,401-0,5$ & 2 & 3 & 1,5 \\
\hline $0,501-0,6$ & 2 & 2,5 & 1,5 \\
\hline $0,601-0,7$ & 4,5 & 5,5 & 2,5 \\
\hline $0,701-0,8$ & 8 & 4,5 & 0,5 \\
\hline $0,801-0,9$ & 16,5 & 2,5 & 3,5 \\
\hline $0,901-1,0$ & 21 & 18 & 5 \\
\hline
\end{tabular}

Sumber: Hasil olahan data primer

Terdapat jumlah petani yang berimbang antara kelas dibawah rata-rata dengan kelas diatas rata-rata. Hal ini berarti petani yang memiliki proporsi kecil dari pendapatan tanaman utama berimbang 
dengan petani yang memiliki proporsi besar dari pendapatan utama.

HKm di Pekon Air Naningan merupakan HKm dengan kopi sebagai tanaman utamanya. Proporsi Lahan olahan (persil) sebagian besar ditanami oleh kopi. Tanaman jenis kayu-kayuan seperti kayu hutan, kayu lamtoro, kayu kaliandra juga ditanam oleh masayarakat. Tanaman sampingan ditanam di sela-sela kopi, seperti cabai, pisang, lada. Kondisi ini menjadikan produksi kopi lebih besar dibanding tanaman lainnya, sehingga porsi pendapatan petani dari tanaman utama kopi sangat besar.

\section{Tenaga Kerja}

Gambar 4 menunjukkan jumlah tenaga kerja yang digunakan (termasuk pemilik lahan) untuk mengelola lahan sebelum mendapat SK HKm. Berdasarkan Gambar 4, sebelum mendapat SK HKm sebanyak 46persen responden mengelola sendiri lahan HKm-nya; 32,5persen mengelola sendiri ditambah satu orang tenaga kerja untuk mengelola lahan $\mathrm{HKm}$, dan sisanya hanya sebesar 22,5persen menggunakan tambahan dua orang atau lebih. Kondisi ini karena memang sebelum mendapat SK HKm kepastian hukum, kenyamanan, dan keamanan mengelola hutan belum ada. Masyarakat masih merasa takut ditangkap oleh polisi hutan, sehingga tidak banyak masyarakat yang ingin dipekerjakan meskipun akan dibayar.

Setelah diberikannya SK HKm oleh pemerintah, terlihat perbedaan jumlah penyerapan tenaga kerja. Masyarakat sudah tidak takut untuk dipekerjakan. Terlihat pada Gambar 5 masyarakat yang bekerja sendiri telah berkurang dibanding sebelum mendapat $\mathrm{HKm}$.

\section{Gambar 4. Jumlah Tenaga Kerja Sebelum Mendapat SK HKm}

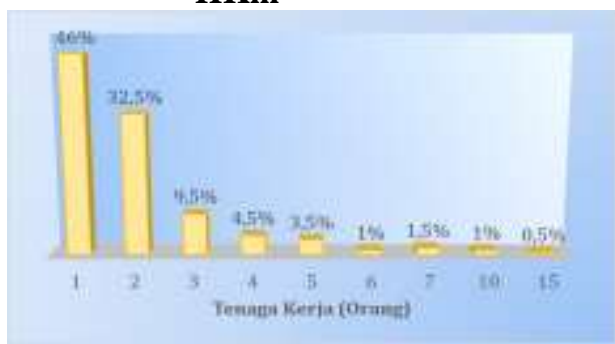

Sumber: Hasil olahan data primer

Setelah mendapat SK HKm rata-rata satu pemilik lahan menggunakan 3 orang tenaga kerja (termasuk pemilik lahan). Jumlah ini meningkat secara rata-rata dari sebelum mendapat SK hanya menyerap 2 orang tenaga kerja (termasuk pemilik lahan).

\section{Gambar 5. Jumlah Tenaga Kerja Setelah Mendapat SK HKm (orang)}

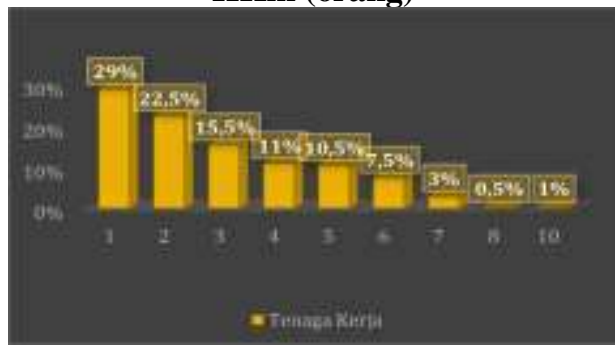

Sumber: Hasil olahan data primer

Hal yang berbeda terjadi setelah pengelolaan lahan $\mathrm{HKm}$ telah dilegalkan oleh pemerintah. Masyarakat memilih untuk membayar tenaga kerja tambahan dibanding harus lelah mengelola lahannya sendiri. Anggota keluarga yang membantu memang masih ada, tapi jumlahnya menurun. Istri berdagang, bekerja, atau bahkan menjadi ibu rumah tangga. Anak bisa bersekolah untuk mendapat tingkat pendidikan yang tinggi.

Kondisi ini dipertegas oleh hasil crosstabulation pada Tabel 2 antara jumlah tenaga kerja sebelum menerima 
SK. Terlihat bahwa penyerapan tenaga kerja bertambah. Sebagai contoh, jika sebelumnya hanya menggunakan satu orang tenaga kerja, setelah mendapatkan SK untuk mengelola lahan HKm hanya 24 persen responden yang tetap bekerja sendiri, 5 persen responden bertambah menjadi menggunakan dua tenaga kerja, bahkan hingga bertambah menjadi menggunakan tujuh orang tenaga kerja.

Tabel 2. Crosstabulation antara Jumlah Tenaga Kerja Sebelum dan Sesudah Menerima SK HKm

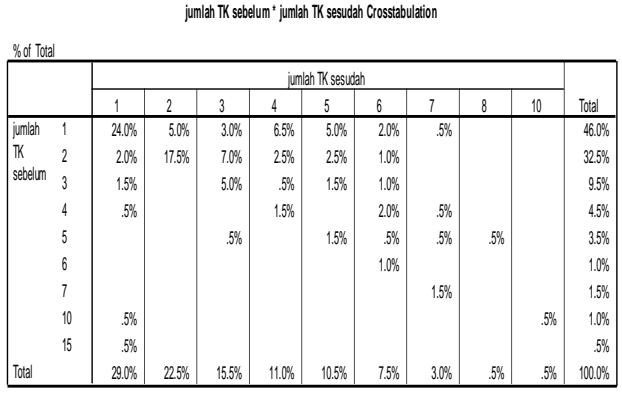

Sumber: Hasil olahan data primer

Akibat dari penggunaan tenaga kerja yang meningkat, petani harus membayar lebih biaya untuk tenaga kerja. Jika sebelumnya petani tidak mengeluarkan biaya untuk merawat tanaman dan lahan, dan juga untuk memanen tanaman, baik tanaman utama maupun tanaman sampingan, sekarang setelah mendapatkan SK HKm para petani mengeluarkan biaya tambahan akan hal tersebut tadi. Selain biaya tenaga kerja, terdapat biaya input dan biaya transportasi, tetapi berdasarkan pengujian model logistik yang dilakukan menyatakan bahwa kedua biaya tersebut, biaya input dan biaya transportasi bersifat redundant atau tidak lagi dibutuhkan/ berguna.

Rasio biaya tenaga kerja merupakan perbandingan biaya tenaga kerja dengan total biaya. Rasio biaya digunakan untuk mengetahui seberapa besar proporsi biaya tenaga kerja dibandingkan total biaya. Berdasarkan perhitungan, rata-rata rasio biaya tenaga kerja adalah 0,3 . Berarti secara rata-rata proporsi biaya tenaga kerja adalah 30 persen dari total biaya.

Tabel 3 memperlihatkan hasil tabulasi silang antara rasio biaya tenaga kerja dan jumlah tenaga kerja. Berdasarkan Tabel 3, responden dengan interval rasio biaya tenaga kerja pada Kelas 1 ( 0 hingga 10 persen) merupakan responden terbanyak (38,5 persen), kemudian menyusul interval rasio biaya pada Kelas 5 (40,1 hingga 50 persen), dan berikutnya responden dengan rasio biaya pada Kelas 4 (30,1 hingga 40 persen), masing-masing sebesar 38,5 persen; 14 persen; dan 10,5 persen.

Tabel 3. Crosstabulation antara Rasio Biaya Tenaga Kerja dan Jumlah Tenaga Kerja Sesudah Menerima SK HKm

\begin{tabular}{|c|c|c|c|c|c|c|c|c|c|c|c|c|c|c|c|c|}
\hline \multirow{2}{*}{ Kelas } & Interval Rasio & \multicolumn{14}{|c|}{ Jumlah Tenagag Kerja } & \multirow[b]{2}{*}{ Total } \\
\hline & $\begin{array}{c}\text { Biaya Tenaga } \\
\text { Kerja }\end{array}$ & 1 & 2 & 3 & 4 & 5 & 6 & 7 & 8 & 9 & 10 & 11 & 12 & 14 & 15 & \\
\hline 1 & $0.000-0.1$ & $19,5 \%$ & $17,0 \%$ & $0,5 \%$ & $0,0 \%$ & $0,0 \%$ & $1,0 \%$ & $0,5 \%$ & $0,0 \% 6$ & $0,0 \%$ & $0,0 \% 6$ & $0,0 \%$ & $0,0 \% 6$ & $0,0 \% 6$ & $0,0 \% 6$ & $38,5 \%$ \\
\hline 2 & $0.101 \cdot 0.2$ & $0,5 \%$ & $0,5 \%$ & $2,0 \%$ & $0,5 \%$ & $0,5 \%$ & $0,0 \%$ & $0,5 \%$ & $0,0 \%$ & $0,0 \%$ & $0,0 \%$ & $0,0 \%$ & $0,0 \%$ & $0,0 \%$ & $0, \% \%$ & $4,5 \%$ \\
\hline 3 & $0.201 \cdot 0.3$ & $0,5 \%$ & $0,5 \%$ & $1,5 \%$ & $1,5 \%$ & $2,5 \%$ & $0,0 \%$ & $2,0 \%$ & $0,0 \%$ & $0,0 \%$ & $0,5 \%$ & $0,0 \%$ & $0,0 \% 6$ & $0,0 \% 6$ & $0,5 \%$ & $9,5 \%$ \\
\hline 4 & $0.301 \cdot 0.4$ & $1,0 \%$ & $0,5 \%$ & $2,5 \%$ & $0,0 \%$ & $1,5 \%$ & $1,0 \%$ & $0,0 \%$ & $2,0 \%$ & $1,5 \%$ & $0,0 \%$ & $0,5 \%$ & $0,0 \% 6$ & $0,0 \% 6$ & $0,0 \%$ & $10,5 \%$ \\
\hline 5 & $0.401-0.5$ & $0,0 \%$ & $0,5 \%$ & $2,0 \%$ & $0,5 \%$ & $3,0 \%$ & $2,0 \% 6$ & $0,5 \%$ & $1,5 \%$ & $1,0 \%$ & $0,5 \%$ & $1,5 \%$ & $0,5 \%$ & $0,5 \%$ & $0,0 \%$ & $14,0 \%$ \\
\hline 6 & $0.501 \cdot-0.6$ & $0,0 \%$ & $0,5 \%$ & $0,5 \%$ & $1,5 \%$ & $0,5 \%$ & $1,5 \%$ & $0,5 \%$ & $0,5 \%$ & $2,5 \%$ & $0,5 \%$ & $0,5 \%$ & $0,5 \%$ & 0,060 & $0,0 \% 6$ & $9,5 \%$ \\
\hline 7 & $0.6011 \cdot 0.7$ & $1,0 \%$ & $0,5 \%$ & $0,5 \%$ & $0,5 \%$ & $1,0 \%$ & $0,0 \%$ & $1,0 \%$ & $0,0 \% 60$ & $1,0 \%$ & $0,5 \%$ & $0,0,50$ & $0,0 \% 6$ & $0,0 \% 6$ & $0,5 \%$ & $7,0 \%$ \\
\hline 8 & $0.701 \cdot 0.8$ & $0,0 \%$ & $0,5 \%$ & $0,0 \%$ & $0,0 \%$ & $0,5 \%$ & $1,0 \%$ & $0,0 \%$ & $0,0 \% 6$ & $0,5 \%$ & $0,0 \% 6$ & $0,5 \%$ & $0,0 \% 6$ & $0,0 \% 6$ & $0,0 \%$ & $3,0 \%$ \\
\hline 9 & $0.801-0.9$ & $1,0 \%$ & 1,07 & $0,0 \%$ & $0,0 \%$ & $0,0 \%$ & $0,0 \%$ & $0,0 \%$ & $0,0 \% 6$ & $0,0 \%$ & $0,0 \% 6$ & $0,5 \%$ & $0,0 \%$ & $0,0 \%$ & $0,0 \%$ & $2,5 \%$ \\
\hline 10 & $0.901-1.0$ & $1,0 \%$ & 0,04 & $0,0 \%$ & $0,0,0$ & $0,0 \%$ & $0,0 \%$ & $0,0 \%$ & $0,0 \% 6$ & $0,0 \%$ & $0,0 \%$ & $0,0 \% 6$ & $0,0 \% 6$ & $0,0 \% 6[$ & $0,0 \% 0$ & $1,0 \%$ \\
\hline & Total & $24,5 \%$ & $21,5 \%$ & $9,5 \%$ & $4,5 \%$ & $9,5 \%$ & $6,5 \%$ & $5,0 \%$ & $4,0 \%$ & $6,5 \%$ & $2,0 \%$ & $4,0 \%$ & $1,0 \%$ & $0,5 \%$ & $1,0 \%$ & $100,0 \%$ \\
\hline
\end{tabular}

Sumber: Hasil olahan data primer

Banyaknya responden dengan interval rasio biaya tenaga kerja pada Kelas 1 merupakan yang terbanyak jumlahnya. Berdasarkan hasil tabulasi silang, banyaknya responden dengan rasio biaya pada Kelas 1 dan hanya menggunakan satu tenaga kerja (pemilik lahan) adalah sebesar 19,5 persen, sedangkan banyaknya responden rasio biaya Kelas 1 dan menggunakan dua tenaga kerja adalah sebesar 17 persen. Masih banyak masyarakat yang menggarap lahan HKmnya sendiri, selain dirasakan masih mampu untuk mengerjakannya, hal ini juga dapat meniadakan biaya tenaga kerja. 


\section{Kemiskinan}

Diberikannya izin pengelolaan HKm oleh pemerintah bertujuan untuk meningkatkan kesejahteraan. Lahan-lahan yang sebelumnya hanya didiamkan saja untuk menjadi kawasan larangan karena berstatus hutan lindung dapat dialihfungsikan menjadi lahan produktif tanpa harus mengurangi kelestarian lingkungan. Dengan tersedianya lahan untuk dikelola dengan aman dan nyaman dapat menyerap tenaga kerja, meningkatkan pendapatan, dengan tujuan akhir mengurangi kemiskinan.

\section{Gambar 6. Kepemilikan Jenis Rumah Oleh Pemilik Lahan}

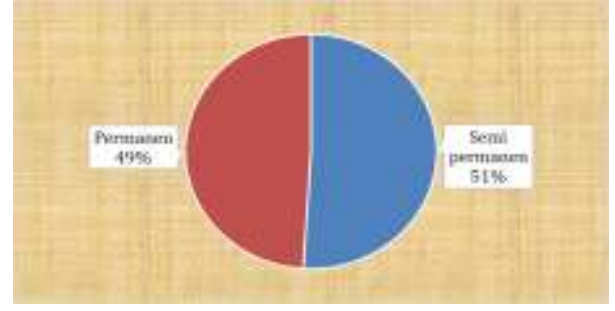

Sumber: Hasil olahan data primer

Tingkat kemiskinan petani di Pekon Air Naningan menurun. Hal ini selain terlihat dari peningkatan pendapatan yang telah dibahas sebelumnya, juga terlihat dari jenis rumah yang dihuni, jumlah kepemilikan kendaraan bermotor, baik roda tida maupun roda empat. Gambar 6 menggambarkan kondisi rumah saat ini. Sebanyak 51 persen sudah permanen (terbuat dari batu bata), dan 49 persen masih semi permanen (terbuat dari papan). Dulu masih banyak sekali rumah warga terbuat dari geribik, sebuah kondisi yang sangat tidak layak. Kondisi sekarang sudah sangat membaik. Tentu penyebabnya salah satunya adalah peningkatan pendapatan akibat diberikannya izin $\mathrm{HKm}$. Pengelolaan legal, pendapatan meningkat.

Salah satu bentuk meningkatnya kesejahteraan di $\mathrm{HKm}$ di Pekon Air
Naningan adalah terdapat sebuah agenda rutin akibat peningkatan kesejahteraan sejak diberikannya izin HKm. Agenda itu bernama 'Arisan Bedah Rumah'. Bagi masyarakat yang mendapatkan undian, rumah miliknya akan direnovasi. Hal ini menandakan bahwa masyarakat memiliki kemampuan untuk membelanjakan uangnya diluar kebutuhan primer untuk dirinya sendiri.

Selain rumah, salah satu kebutuhan yang menandakan bahwa seseorang telah memiliki pendapatan yang cukup tinggi adalah kebutuhan akan barang mewah seperti motor dan mobil. Kepemilikan motor oleh pemilik lahan digambarkan pada Gambar 7 dan kepemilikan akan mobil digambarkan pada Gambar 8 .

\section{Gambar 7. Jumlah Kepemilikan Motor Oleh Pemilik Lahan}

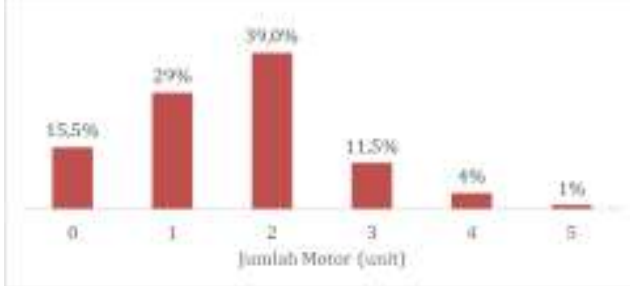

Sumber: Hasil olahan data primer

Sama halnya dengan rumah, kepemilikan motor juga cukup meningkat dengan adanya peningkatan pendapatan akibat diberikannya izin kelola lahan $\mathrm{HKm}$. Terlihat 84,5 persen warga memiliki paling sedikit satu unit motor. Hanya 15,5 persen yang tidak memiliki motor. Jika dilihat dari jarak antara rumah dan lahan HKm tidaklah terlalu jauh, ditambah kondisi jalan yang sulit karena kondisi jalan masih jelek dan sempit, masyarakat dapat berjalan kaki untuk pergi ke hutan. Namun nyatanya masyarakat memilih untuk membeli sepeda motor, selain kebutuhan operasional ke hutan untuk merawat dan memanen tanaman, motor juga digunakan untuk kebutuhan sehari- 
hari seperti belanja ke pasar dan mengantar anak sekolah.

\section{Gambar 8. Jumlah Kepemilikan Mobil Oleh Pemilik Lahan}

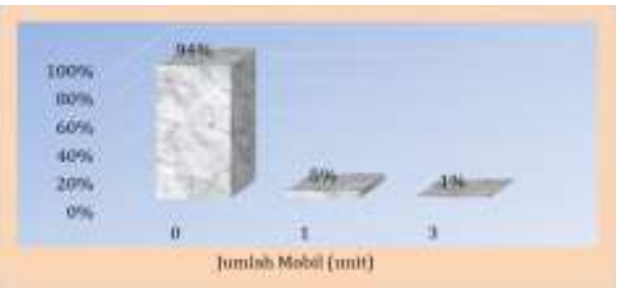

Sumber: Olahan data primer

Sementara itu untuk kepemilikan mobil oleh pemilik lahan memang belum banyak yang memiliki mobil. Baru ada 5 persen responden yang memiliki satu unit mobil, dan 1 persen yang memiliki tiga unit mobil. Bagi masyarakat HKm di Pekon Air Naningan perizinan yang baru berumur rata-rata empat tahun hingga tahun 2018, dirasa belum menjadi prioritas untuk memenuhi kebutuhan akan mobil. Masyarakat masih memprioritaskan kebutuhan akan rumah, pangan, pakaian, dan sekolah anak.

\section{Kemitraan}

Kemampuan untuk mengelola lahan HKm sangat diperlukan untuk meningkatkan produktivitas lahan. Akan sangat percuma apabila diberikan izin kelola hutan, namun tidak memiliki kemampuan untuk mengelola lahan. Selain itu diperlukan juga akses modal dan akses pasar. Maka oleh sebab itu sangat diperlukan adanya kemitraan dari lembaga maupun perorangan untuk membantu masyarakat dari mulai proses produksi hingga pemasaran.

Gambar 9 menjelaskan jenis kemitraan yang dirasakan oleh petani. Jenis kemitraan yang paling banyak dirasakan oleh responden adalah kombinasi dari kemitraan berupa: (1) Dibeli produk; (2) Diberi bantuan modal; (3) Diberikan pelatihan; (4) Diberikan pendampingan; (5) Diberikan penyuluhan. Sebanyak 54 persen responden merasakan kombinasi kemitraan tersebut. Selain kombinasi kemitraan, persentase terbesar selanjutnya adalah bahwa terdapat 25,5 persen responden yang tidak memiliki mitra; lalu 6,5 persen responden hanya mendapatkan penyuluhan; masing-masing 4 persen respoden mengatakan hanya mendapat pelatihan dan hanya dibeli produknya; 2,5 persen hanya mendapatkan bantuan modal; 2persen mengatakan lainnya; dan 1,5 persen hanya mendapatkan pendampingan.

\section{Gambar 9. Jenis Kemitraan}

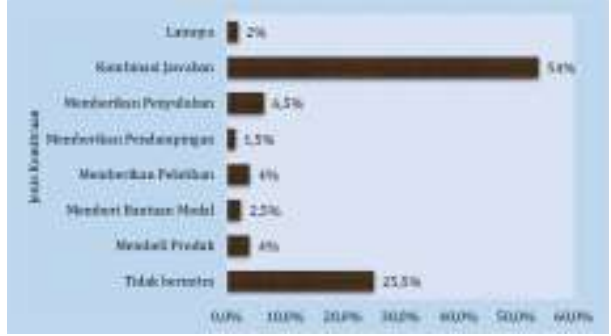

Sumber: Hasil olahan data primer

Gambar 10 menjelaskan jenis-jenis kendala yang dialami oleh responden. Jenis kendala terbanyak yang dialami responden adalah kombinasi dari terbatasnya akses bahan baku, akses modal, akses pasar, dan masih tradisionalnya peralatan yang dimiliki. Sebanyak 34persen responden menjawab kombinasi.

\section{Gambar 10. Jenis Kendala}

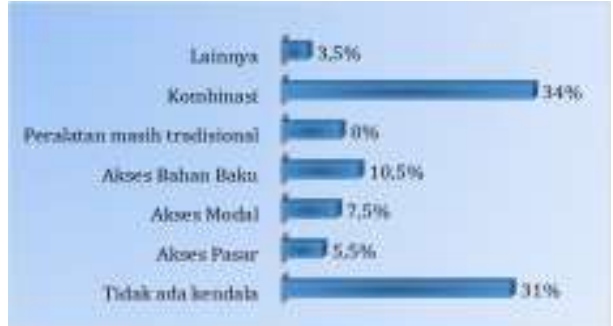

Hasil olahan data primer

10,5 persen persen responden kemudian mengatakan hanya memiliki kendala akses bahan baki; 8persen hanya memiliki kendala peralatannya yang masih 
tradisional; 7,5persen hanya memiliki kendala terbatasnya akses modal; 5,5persen hanya memiliki kendala terbatasnya akses pasar; dan 3,5persen responden menjawab kendala lainnya.

\section{KESIMPULAN}

Secara keseluruhan petani di Pekon Air Naningan mengalami peningkatan produksi, pendapatan, dan penyerapan tenaga kerja. Pemberian IUPHKm dapat memberikan peningkatan kesejahteraan, yang terlihat dari: (1) peningkatan pendapatan sesudah menerima IUPHKm sebesar 142,73 persen; (2) Petani HKm telah memiliki rumah sendiri meskipun sebagian masih semi permanen; (3) Kepemilikan sepeda motor antara 1 hingga 3 unit.

Jenis kemitraan yang telah dilakukan berupa penyuluhan, pelatihan, membeli produk, memberi bantuan modal, dan pendampingan. Kendala yang dihadapi oleh petani kelompok Hkm adalah kombinasi dari terbatasnya akses bahan baku, akses modal, akses pasar, dan masih tradisionalnya peralatan yang dimiliki.

\section{REFERENSI}

Monografi Pekon Air Naningan. 2019

PP Nomor 6 Tahun 2007 tentang Tata Hutan dan Penyusunan Rencana Pengelolaan Hutan, Serta Pemanfaaan Hutan

Simon, Hasanu. 1995. Aspek Sosial, Ekonomi, dan Budaya Pembangunan Hutan Rakyat. DPP-HKTI bekerjasama dengan KAS dan Depertemen Kehutanan Jakarta. 